Leonard Woolley's lecture on "The Racial Elements in Sumerian Art History" before the Royal Society of Arts on February 19 (J. Roy. Soc. Arts, 84, April 3, 1936) afforded an example of the pregnant inferences to be drawn from study of the geographical distribution of cultural elements to be related to those found at Ur and kindred sites in Mesopotamia in its bearing on the solution of the racial problem in Sumeria. As he pointed out, various theories have been put forward at different times, as knowledge has grown, to interpret evidence of the physical characters of the early population of Sumeria. Sir Leonard himself, by citing specific elements which go to make up the complex of Sumerian art, was able to show that it is a compound of three cultural streams. Of these the Asianic or Iranian goes back at Ur to pre-diluvial times, its most marked characteristics there being the painted pottery, while it extends from Mesopotamia to China; a second is derivative from Anatolia and the third comes from northern Syria. In these three cultural elements he finds, hypothetically, a parallel to the distinction which is drawn in the evidence for three differentiated physical types in the population. In this instance, it is to be admitted, there would appear to be good ground for the view put forward that the brilliant achievement of Sumerian art, in which these cultural streams unite, was due to that cross-fertilization of racial strains, which Sir Leonard maintains lies at the root of all great achievements in the art of a people as a whole. It is to be expected that Sir Leonard's new field of exploration in northern Syria will throw further light on the racial as well as the cultural problem.

\section{Roman Leicester}

Excavatron of Roman remains at Leicester now in progress has resolved an archæological doubt of long standing. While instructed opinion has hesitated between identifying the well-known Jewry wall, one of the highest surviving Roman walls in Britain, popularly regarded as a temple of Janas, as a Roman bath building, a basilica or even a town gate, it has now been shown, according to a report in The Times of July 4, to be part one of the external walls of the basilica in the forum of Roman Leicester, dating probably from about A.D. 100. A large part of the adjacent site, until recently occupied by a factory, is being cleared by the Corporation for the erection of public baths, and advantage has been taken of the opportunity to carry out these excavations. The base of the Jewry wall has been uncovered to some ten feet below the present surface, giving a total height of existing masonry of more than thirty-five feet. Two arehed openings, previously thought to be doorways, are now revealed as windows. Beneath the Jewry wall, timber and masonry are associated with pottery and coins going back to the earliest Roman occupation of Britain. To the west of the wall is emerging a courtyard about $175 \mathrm{ft}$. wide, flanked by ranges of rooms or shops opening on to the courtyard by porticoes. This is the forum, of which the basilica forms part. Fronting the forum and abutting centrally on the basilica are the massive foundations of an architectural feature, probably once surmounted by a pediment, which dominated the forum and faced the main entrance. Outside the northern wall of the forum a stretch of cobbled roadway, deeply scored by wheels, has been uncovered. Massive walls and fragments of columns found on the factory site some years ago may now be identified as fragments of the forum and its colonnades. The road on the southern side of the forum is largely covered by St. Nicholas Street, near which is preserved one of the mosaic pavements for which Roman Leicester is famous. The excavations are being carried out by Miss Kathleen Kenyon under a committee, of which the Duke of Rutland is president, in co-operation with the Corporation of Leicester.

\section{Electricity Distribution in Great Britain}

The report of the Committee on Electricity Distribution has now been published (Ministry of Transport. London: H.M. Stationery Office. $2 s$. net). The chairman was Sir Harry McGowan, and Sir John Snell was a member of the Committee. The evidence, some of which was conflicting, has all been carefully considered, and definite recommendations are given which seem thoroughly justified. The Committee does not suggest nationalization or the setting up of a Distribution Commission. It advises a reduction in the present number of undertakings by amalgamating the smaller and less efficient stations with the larger ones. It is stated that any attempt to carry through a scheme of re-organization on a voluntary basis is bound to fail, and legislation must confer definite and adequate compulsory powers. The schemes of re-organization should make provision for the possibility of ultimate public ownership of all undertakings, including those not at present subject to purchase by the local authorities. It is proposed that no undertakings should be transferred compulsorily under a scheme of re-organization without a prior local investigation. To this end the Electricity Commissioners should be empowered to delimit the country into a number of areas and to appoint for each area a temporary district commissioner, with such technical and financial assistance as may be necessary. The district commissioner would bring under review all electric undertakings in his area. The Electricity Commissioners, after publishing a scheme and considering any representations, should be empowered to approve it and, if agreed, it should become operative at once.

Wiтh regard to the London and Home Counties Electricity District, which covers an area with a large number of undertakings, some with duplication of powers, many with differing systems and tariffs, and offering very unequal facilities, the criticisms recently made by the public are often justified. A substantial measure of amalgamation and coordination is possible and necessary. The present constitution of the London and Home Counties Joint Electricity and Authority should be brought under review. Complete standardization of systems and voltages should be the ultimate objective, but it is 
difficult to see how this can be done equitably. The amalgamation of undertakings into a smaller number of larger undertakings is an important step towards standardization of methods of charging and more uniform prices. The Minister of Transport should be empowered to require all undertakers to offer an improved statutory two-part tariff for domestic supplies, as an optional alternative to a flat-rate charge. The fixed charge under an approved twopart tariff should be based either on the floor area of the house or on its rateable value, and all undertakers should be required to publish the actual scale of fixed charges under their two-part tariff. If these suggestions were adopted there should result a general, though necessarily gradual, reduction in costs. Amongst other recommendations, it is sug. gested that where gas and electricity undertakings are left under the joint ownership of a local authority, it would assist in the more rapid development of the electricity undertaking if the authority were required to have separate committees. Evidence was given which showed that restrictions had been imposed on the development of the electrical undertaking in order to prevent the financial position of the gas undertaking from being adversely affected. Both public activities should be equally untram. melled.

\section{Meteorology in India}

Is the Report on the Administration of the Meteorological Department of the Government of India in 1934-35 (Delhi : Manager of Publications, 1935), an account is given of an important change in the arrangements for dealing with the increasing meteorological requirements of aviation along the trans-India air route. In previous years, a separate forecast had been issued to each aircraft in respect of the route covered by it each day from the forecasting centre concerned; but it became evident that it would soon be impossible for the two centres at Karachi and Calcutta to continue to do this for the four thousand miles of the route between Bahrein and Victoria Point. Arrangements were therefore made to broadcast forecasts for each section of the route regularly at fixed times, and to distribute data relating to upper winds and cloud height by wireless from pilot balloon stations along the trans-India route twice daily. The Agricultural Meteorology Branch carried out a number of researches, mainly at the Central Agricultural Meteorological Observatory, Poona; instruments for the study of microclimatology were designed and tested, and a number of papers were written dealing with the correlation between meteorological conditions in the open and among growing crops; researches into evaporation, percolation and effective rainfall were also made. Experiments on the effect on soil temperature of a thin covering of soil of different colours and from different districts showed that coverings of certain soils had a big effect on the climate of the soil beneath. Other investigations were made into the albedo of different types of soil and vegetation. The scheme of crop-weather precision observations was applied to wheat and jowar at Poona, to rice at Karjat and to bajri at Baroda. The study of frost damage and methods of preventing it was also included in this branch's activities. The Upper Air Observatory at Agra released seventy-seven sounding balloons with recording instruments, and nearly half of these were recovered.

\section{Physiology of Indian Crop Plants}

For some time past, the staff of the Institute of Agricultural Research of the Benares Hindu University has been engaged, under the leadership of Prof. B. N. Singh, in detailed and comparative studies of the physiology of Indian crop plants. A considerable number of publications on this subject has now been issued, mainly in the Proceedings of the Indian Academy of Sciences, and good progress has evidently been made in a highly interesting and important field of work. The most extensive work completed is that dealing with photosynthesis under different conditions of light, temperature and carbon dioxide supply. Since a large part of previous research on this subject has been carried out in temperate climates, it will be obvious that detailed studies of tropical plants are likely to be of considerable value. One striking result of this work is that tropical plants are found to have a higher light requirement in photosynthesis than similar species grown under temperate climatic conditions. Another especially interesting problem under investigation is that of the differences in respiration rate found to exist in plants differing in their duration of life. Short-lived plants are apparently characterised by a low respiration rate, which also falls off very rapidly as the age of the plant increases. Long-lived plants, on the other hand, not only have a high respiration rate but also are able to maintain this higher rate throughout life. Other subjects under investigation by comparative methods include the water requirements of seeds possessing different structural and biochemical properties, and the effects on plant growth of irradiating seeds with X-rays.

\section{Electricity in Horticulture}

ELECTRo-CULTURE has to take into account the effects of electric heating, electric lighting and the voltage stress on the life of plants. The first application of electricity took the form of high-voltage discharges produced in close proximity to various plants in an endeavour to obtain artificial stimulation. In the Engineering Supplement for May of Siemens Magazine, a survey is given of recent developments, and the photographs shown of the effects produced are convincing. It has often been noticed that an increased growth of crops sometimes occurs during thundery weather. In the Arctic, where the average atmospheric potential gradient is high, it has been observed that the growth of vegetation during the short summer is more vigorous than in southern climates. Experiments have been carried out on cereals, potatoes, beets, tomatoes, strawberries and raspberries, and increases up to forty per cent have been obtained. Electricity in the form of light was the next application in the aid of horticulture. For vigorous plant growth a minimum of about 4 hours 